\title{
Normal pressure hydrocephalus secondary to Lyme disease, a case report and review of seven reported cases
}

\author{
Louise Nørreslet Gimsing ${ }^{1 *}$ (D) and Anne-Mette Hejl ${ }^{2}$
}

\begin{abstract}
Background: Infection with tick borne Borrelia Burgdorferi (Lyme disease) can without treatment rarely develop into a chronic phase. Secondary Normal Pressure Hydrocephalus (sNPH) based on chronic infection with Borrelia Burgdorferi $(\mathrm{Bb})$ is an even rarer entity, that with the right treatment is potentially curable.

Case presentation: A 67-year-old male with a slow onset of progressive balance problems, also presented unspecified dizziness, urge feeling, neck soreness and discrete cognitive complaints. An MRI scan revealed an enlarged ventricular system compatible with NPH. After further liquor dynamic procedures, cerebrospinal fluid (CSF) was analysed with the surprising results of lymphocytic pleocytosis, and signs of increased antibody production. Microbiology revealed chronic neuroborreliosis and the patient was treated with antibiotics accordingly. At the oneyear follow-up no symptoms remained and the ventricular system almost normalized.

Conclusions: We describe the 7th published case of sNPH secondary to chronic Borreliosis in a previous healthy adult. Existing published literature has been reviewed and previous cases showed similarly nearly full clinical recovery. Primary/idiopathic NPH (iNPH) is treated with the surgical intervention of ventriculoperitoneal shunt and can be mistaken for a sNPH. The awareness of rare causes of sNPH like chronic Borreliosis is important as it is easily treated non surgically.
\end{abstract}

Keywords: Secondary normal pressure hydrocephalus, Chronic Borreliosis, Normal pressure hydrocephalus, Lyme disease

\section{Background}

The chronic phases of infection with the spirochete Borrelia Burgdorferi $(\mathrm{Bb})$, European Lyme disease is characterized by involving several organ systems. Involvement of the nervous system, neuroborreliosis, can develop in untreated individuals usually within 2-6 weeks [1], and typically includes signs of meningeal irritation comprising of nuchal tenderness, fatigue, nausea and the two cardinal symptoms: painful meningoradiculitis and peripheral motor deficits (the clinical part of Bannwarth's triad [1]).

\footnotetext{
* Correspondence: Louisenorgim@live.dk

${ }^{1}$ Department of Specialized Neurorehabilitation, Hvidovre Hospital, Kettegårds Allé 30, 2650 Hvidovre, Denmark

Full list of author information is available at the end of the article
}

The rare condition of chronic neuroborreliosis (duration $>6$ months) can evolve to a variety of different sub conditions, normal pressure hydrocephalus (NPH) being one of them.

In this article we present a rare adult case of NPH in a prior healthy individual, who turned out to have developed the clinical and radiological syndrome secondary to chronic neuroborreliosis. Full recovery was achieved after antibiotic $(\mathrm{AB})$ treatment.

\section{Case presentation}

A 67-year-old male, healthy and with no prior admissions, was seen in autumn of 2009 by his General 
Practitioner (GP). The patient complained of increasing dysfunctional levels based on several different symptoms, all onset within 3-4 months and progressing slowly. The main complaints included balance problems (no falls reported), diffuse dizziness (not rotatory or nautical) and urinary urge-incontinence. During the same period, he had problems concentrating and with finding words with an increased irritability. He complaint of sore muscles of the arms muscles and around the neck a moderate morning headache $(\mathrm{VAS}=5)$ and an increasing feeling of exhaustion. He had no problems of slow movements, coordination problems, body stiffness, hallucinations, lateralized symptoms nor changes of personality. An MRI scan of the brain without contrast, revealed dilatated lateral and third ventricles, normal forth ventricle and sulci. The radiologist concluded a suspicion of NPH (Fig. 1) based on an Evans index of 0.377 a (DESH signs). The callosal angle was $117^{\circ}$ and so not significantly decreased. The patient was referred to a neurosurgical clinic, who transferred the patient to a specialized Memory Disorders Clinic for evaluation of possible NPH.
At the first examination here (December 2009) he also reported fragmented sleep during the night. He reported, no exposure of tick, insect bite nor rash.

\section{Assessment}

pt?>On physical examination the neurologist found normal vital signs and no fever. No sign of frontal lope dysfunction. No stiffness to the neck and no skin rash. The neurological examination revealed occasional searching for words, but normal sentence construction and fluency, normal naming of objects. There was no sign of dysarthria. Cranial nerves and muscle strength were normal, but a discrete ataxia in the left arm and leg was found. The patient had no sign of parkinsonism: no tremor, had a normal posture and arm swing in gait. Gait was with slight gait apraxia but with normal speed. He walked with normal speed, broadened, but with normal step length and height. Walking on a straight line caused imbalance. There was a negative test of Romberg. Tonicity of the lower extremities was moderately increased bilaterally, but the deep reflexes, plantar responses and clonus were normal. Primary reflexes of snout and frontal tapping were negative.

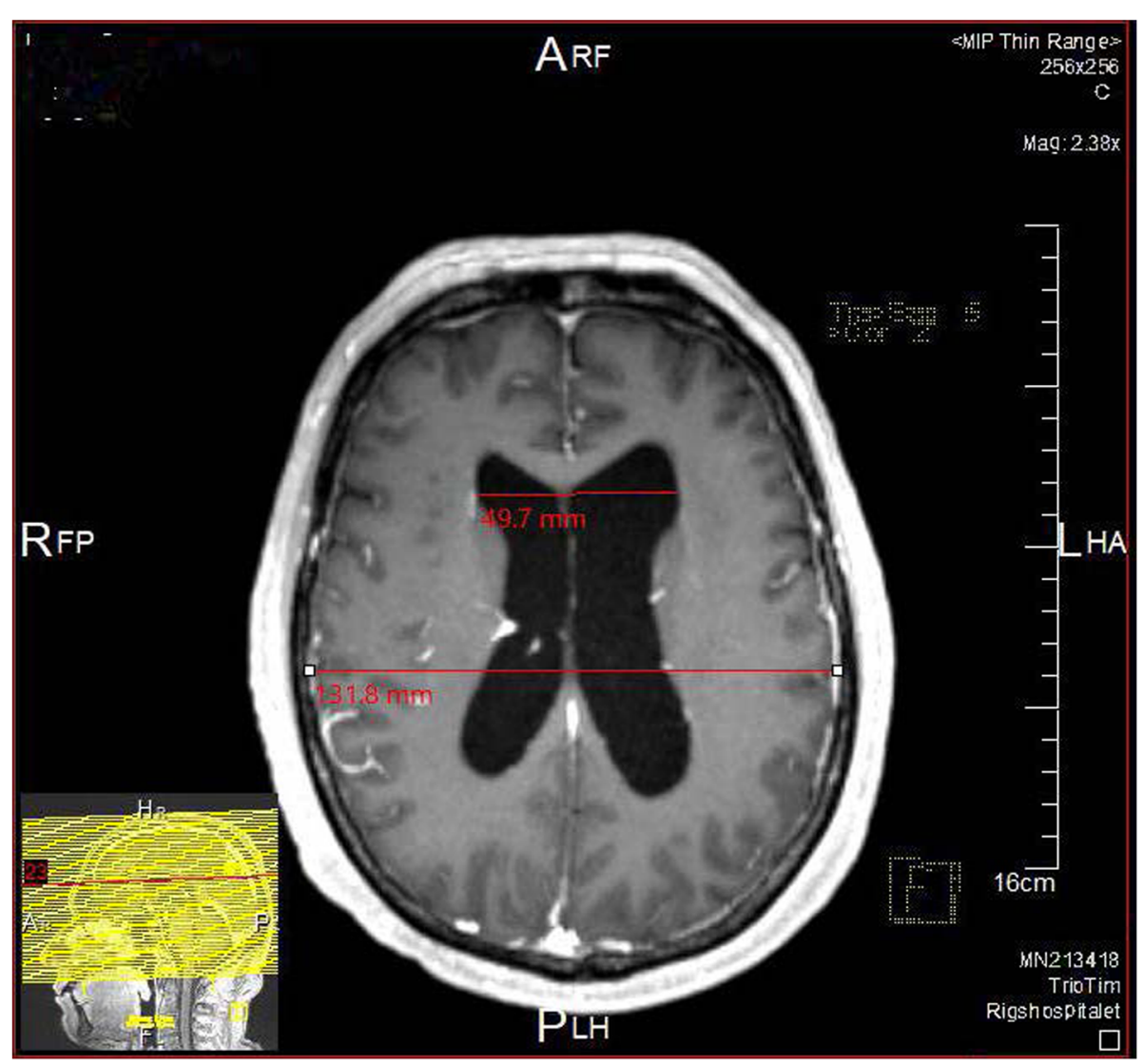

Fig. $1 \mathrm{NPH}$ hos case 
On cognitive testing with the Minimal Mental State Examination (MMSE [2]) and Addenbrooke's Cognitive Examination (ACE [3]) he showed mild cognitive impairment $(\mathrm{MMSE}=28 / 30, \mathrm{ACE}=89 / 100$. Affected animal fluency and s-word fluency.).

\section{Timeline for Case Report}

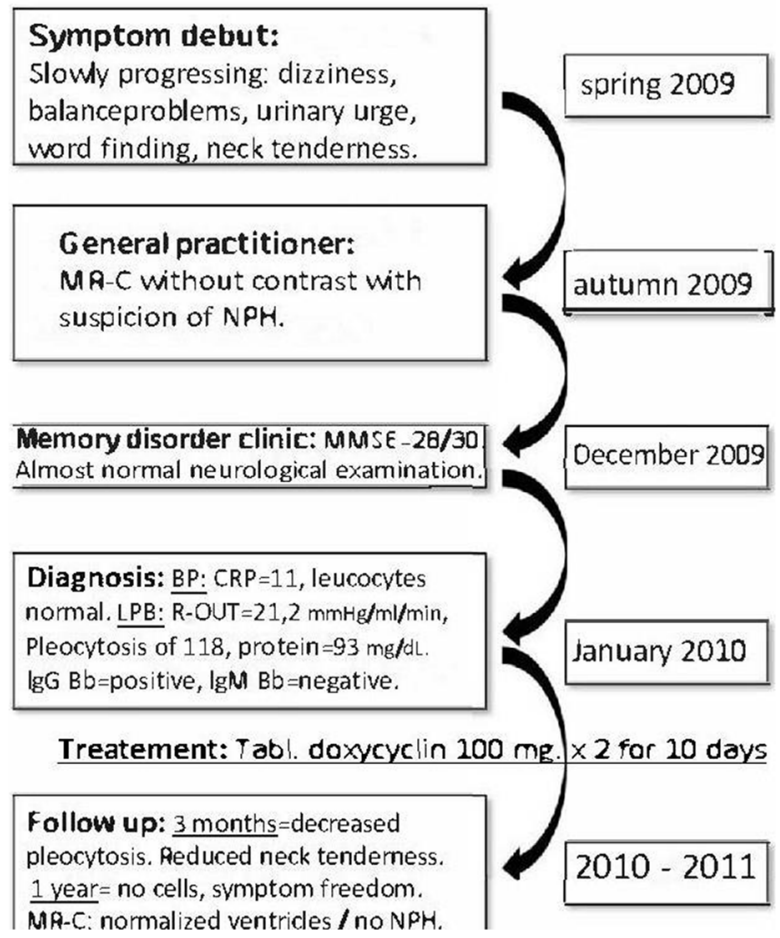

\section{Diagnosis and management}

The initial laboratory test found marginally elevated $\mathrm{C}$ reactive Protein $(\mathrm{CRP})=11$ and sedimentation reaction $=$ 20. Complete blood cell count, electrolytes, liver enzymes, albumin, creatinine, lactate dehydrogenate, thyroid stimulating hormone, B12, folate and calcium were normal.

In the workup battery of NPH, a lumbar puncture (LBP) was performed with a normal opening pressure (17 mmHg), but a lumbar infusion test (4) with an ROUT $=21.2 \mathrm{mmHg} / \mathrm{ml} / \mathrm{min}$, being diagnostic for $\mathrm{NPH}$ (> $16 \mathrm{mmHg} / \mathrm{ml} / \mathrm{min}$ ).

The CSF showed an increased protein count $(93 \mathrm{mg} /$ $\mathrm{dL}, \quad[20-40 \mathrm{mg} / \mathrm{dL}])$, lymphocytic pleocytosis (118 U/ $\mathrm{mm}^{3}, 80 \%$ lymphocytes) and microscopy with polyform leucocytes but no microorganisms (especially no cryptococcus). Further CSF-analysis showed at first negative oligoclonal bands, positive $\mathrm{Bb}$ IgG with a CSF/serum-ratio $=11.7$ and no synthesis of Bb IgM.

In lack of enough CSF and with the surprising pleocytosis, an LBP was repeated 4 days after showing additional increases in protein count $(101 \mathrm{mg} / \mathrm{dL})$, more pronounced pleocytosis (186 U/mm $3 \mathrm{~m}^{3}, 95 \%$ lymphocytes) and now positive oligoclonal bands and an IgG CSF/ blood-ratio of 12.4.

The CSF was cultured for bacteria and fungus showing neither. Further tests for both HIV (PCR and DNA), cryptococcus (antibodies), HSV and VZV (PCR and antibodies) and mycobacteria and Tuberculosis (PCR) were negative. A flowcytometry showed sign of reactive but not malignant immune response.

Screening for Syphilis and sarcoidosis (S-ACE) tested negative, and a repeated general laboratory test (a month later than the first) showed normalized CRP and again no further abnormality.

The MRI scan of the brain was repeated (4 months after the first), showing unchanged dilated lateral and third ventricles (unchanged EI), persistent periventricular hyperintensity and no post contrast enhancements.

Despite the lack of leptomeningeal enhancement, the positive intrathecal $\mathrm{Bb}$ antibody synthesis and the prolonged symptoms gave the diagnosis: chronic neuroborrelioses, and so indicated $\mathrm{AB}$ treatment.

As the patient within a week after the first LBP reported slight decrease in symptoms, he was discharged with peroral Doxycyclin, $200 \mathrm{mg} . \times 2$ the first day and hereafter $100 \mathrm{mg}$. $\times 2$ for 10 days.

\section{Outcome and follow-up}

At 3-month follow-up, a control LBP was performed, with the pleocytosis almost diminished $\left(23 \mathrm{U} / \mathrm{mm}^{3}, 96 \%\right.$ lymphocytes), decreased protein count $(62 \mathrm{mg} / \mathrm{dL})$ but still showing signs of increased antibody concentrations with elevated unspecified IgG and positivity for oligoclonal bands.

Subjectively the patient reported no more headache, balance problems nor urge. The subjective cognitive problems of concentration and search for words were almost gone, yet occasionally muscle soreness remained.

Another 3 months later, the patient reported neck tenderness as the only symptom. The repeated LBP proved further improvement with only slight pleocytosis (11 U/ $\left.\mathrm{mm}^{3}\right)$, normalized protein count $(58 \mathrm{mg} / \mathrm{dL})$, decreasing unspecified Still present oligoclonal bands.

At the 1- year follow-up (after treatment) the patient was symptom free.

At that point a control LBP showed normal CSF cell count, normal protein count and decreasing immunoglobulins: unspecified IgG $=0.110 \mathrm{~g} / \mathrm{L}, \operatorname{IgG}$-index $=1.76$.

An MRI scan was repeated with now almost normalized ventricle size, normal sulci, no periventricular hyperintensity and still no post contrast enhancement. MMSE was unchanged (29/30) but the patient performed better in ACE (97/100).

The patient was discharged with no further control. 


\section{Discussion and conclusions}

$\mathrm{NPH}$ was first recognized in 1965, as a syndrome of hydrocephalus with normal CSF opening pressure and with cognitive decline, urinary incontinence and gait disturbance, potentially reversible by neurosurgical procedures [4].

Since 2000 [5] the term secondary NPH in contrast to idiopathic NPH has been used in the literature, and while the definition of iNPH previously was "just" the lack of an explanation [6], later studies [7, 8] have shown, that both the pathophysiology, the type of expansion of the ventricular system [7], the epidemiological characteristics [9] and the prognosis after treatment [9] differs between iNPH and sNPH.

sNPH caused by neuroborreliosis is believed to be triggered in arachnoid granulate in the subarachnoidal spaces when the chronic infection presents itself in the form of infiltration of the spirochete, and when inflammatory cells and proteins disturb the CSF absorption [5]. It falls in the same category as NPH by neurosyphilis [10] and by cryptococcus infection [11]. Infectious sNPH is believed to develop within a time span from 10 days to up to 6 months after the infection [9].

The first $\mathrm{Bb}$ induced $\mathrm{sNPH}$ case was described in 1993, published in 1997 [12]. In total there are only eight published cases [12-19] appearing in the Pubmed database, identified by the systematic combination of the search words: Lyme, Borrelia, Borreliosis AND Normal pressure hydrocephalus (also including a non-English articles) (Literature search and selection can be seen in Fig. 2, overview of the articles in Table 1).

As the early phase of NPH can present itself with only cognitive symptoms, and as NPH can be mistaken for the radiology of an atrophic, neurodegenerative brain [20], one could suspect that some of the cases of "Lyme induced dementia" [21, 22] or "neuropsychiatric symptoms of neuroborreliosis" [23] could in fact be patients having $\mathrm{Bb}$ induced $\mathrm{sNPH}$. For these conditions the literature describes similar chronic meningitis with inflammation and infiltration as the cause and mechanism of symptoms [5, 24] and this could argument for some degree of diagnostic overlap or misdiagnosis. Furthermore, $\mathrm{NPH}$ is generally considered underdiagnosed.

The international guidelines of iNPH in 2005 [25] and the Japanese guidelines from 2004 [26] both have the Evan's Index (EI) as an obligational criterion for the enlarged ventricular system, supporting the clinical criteria of NPH [27]. EI is the ratio of the transverse diameter of the anterior horns of the lateral ventricles to the greatest internal diameter of the skull and has a cut-off of $\geq 0.30$.

Imagine features of the callosal angle (CA) of $90^{\circ}$ or less at the level of the posterior commissure $[25,26]$, presence of periventricular hyperintensity and deep white matter intensity (DWMH), low flow void of 3rd or 4th ventricle, $\mathrm{z}$-Evan's Index $(\mathrm{z}$-EI) $\geq 0,3$, enlarged sylvian fissure and the narrowing of sulci and subarachnoid spaces over the high convexity (DESH) are all features that can increase the probability of iNPH [27].

The CSF dynamic test of (spinal) tap test and lumbar infusion test (LIT) has been used to both increase the diagnostic probability of iNPH but also to select the patient group that will profit from a potential shunt operation [26].

While the same diagnostic approach has been used for sNPH for many years, studies from 2017 [7, 8] show that not only does sNPH affect a younger patient group with faster progression of symptoms, but the ventricular system also expands in a symmetrical and proportional way with a lower total CSF-volume than iNPH and with diminished subarachnoid areas than the healthy controls. This concludes, that the features of CA, periventricular hyperintensity, DWMH, z-EI and DESH are less likely to develop and be present in $\mathrm{SNPH}$ than in iNPH, and as such suggested to be accounted less for in the diagnostics [7].

sNPH as a group is as well as iNPH being treated with neurosurgical procedure of shunt implantation and in fact with a better prognosis (75\%) for symptom improvement [5].

Table 1 list the characteristics and diagnostics of each published case based on a review of the literature to date (see Fig. 2).

Only one of the prior cases reported a tick bite within a year before symptom debut [13], and the symptom duration at admission time ranged from approximately 4 months to 1 year.

All had intrathecal synthesis of $\mathrm{Bb}$ antibodies either IgG or IgM with lymphocytic CSF-pleocytosis and elevated CSF-protein (though the latter was not stated in one case [17]) and so fulfilled the consensus criteria for neuroborreliosis [28, 29].

All cases reported some degree of progressive gait and cognitive problems, and all but one [15] presented degrees of urinary incontinence.

Objectively all cases had disorientation or word latency to different degrees with the addition of either broad based gait or inability to walk in a line. Five out of 9 had mild to moderate ataxia, one had bradykinesia and rigor, and one had emotional lability and one presented with abnormal almost psychotic behaviour. Of diagnostics all had dilated lateral ventricles, but not all articles specified the radiology in detail. In one case only was the EI noted. Two cases (including ours) reported a normal opening pressure at LBP, while the measurement was not reported in the rest.

Neither of the prior published cases nor the case presented in this article were treated with ventricular shunt, probably because of the clear effect of the AB. All except 


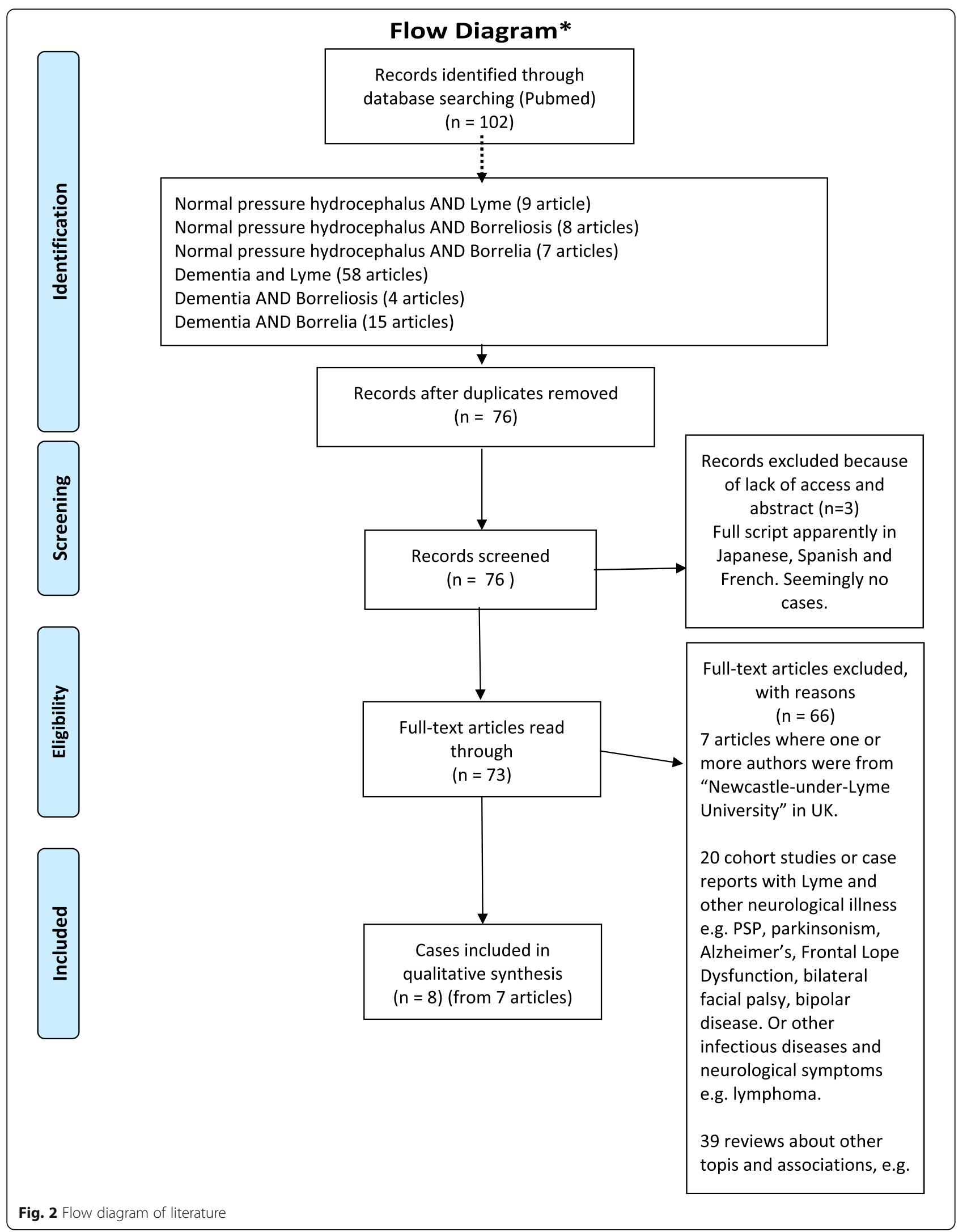




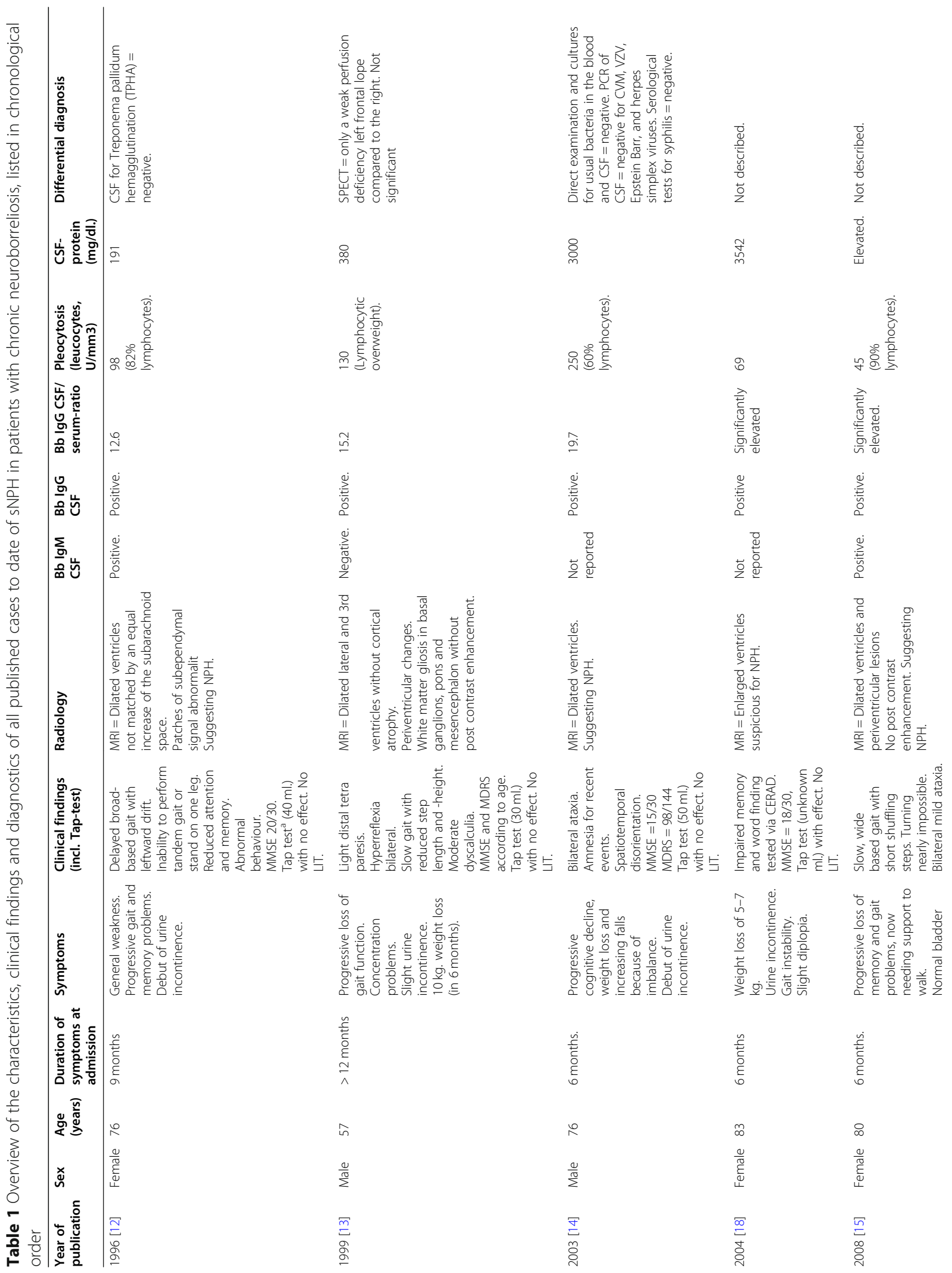




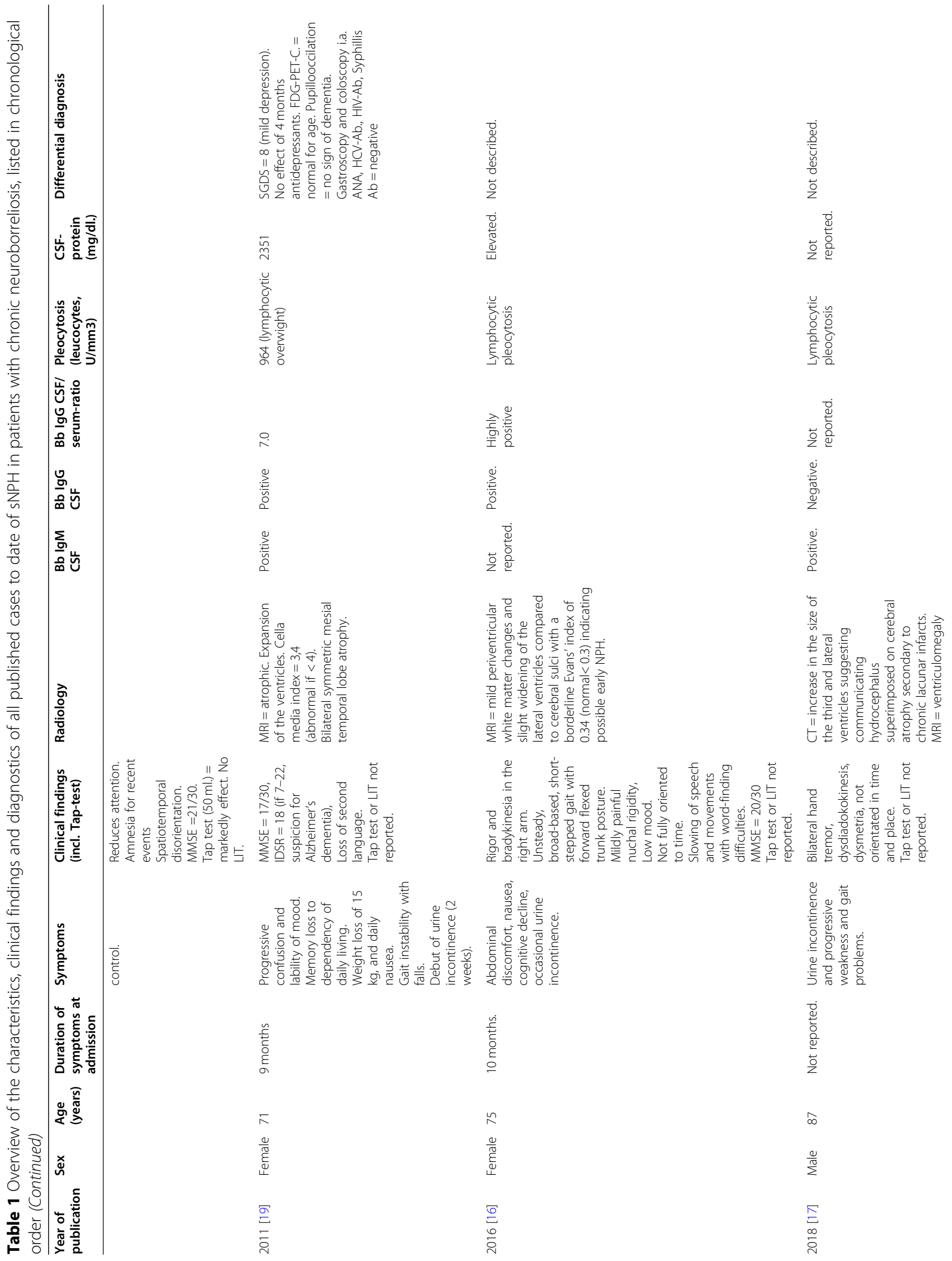




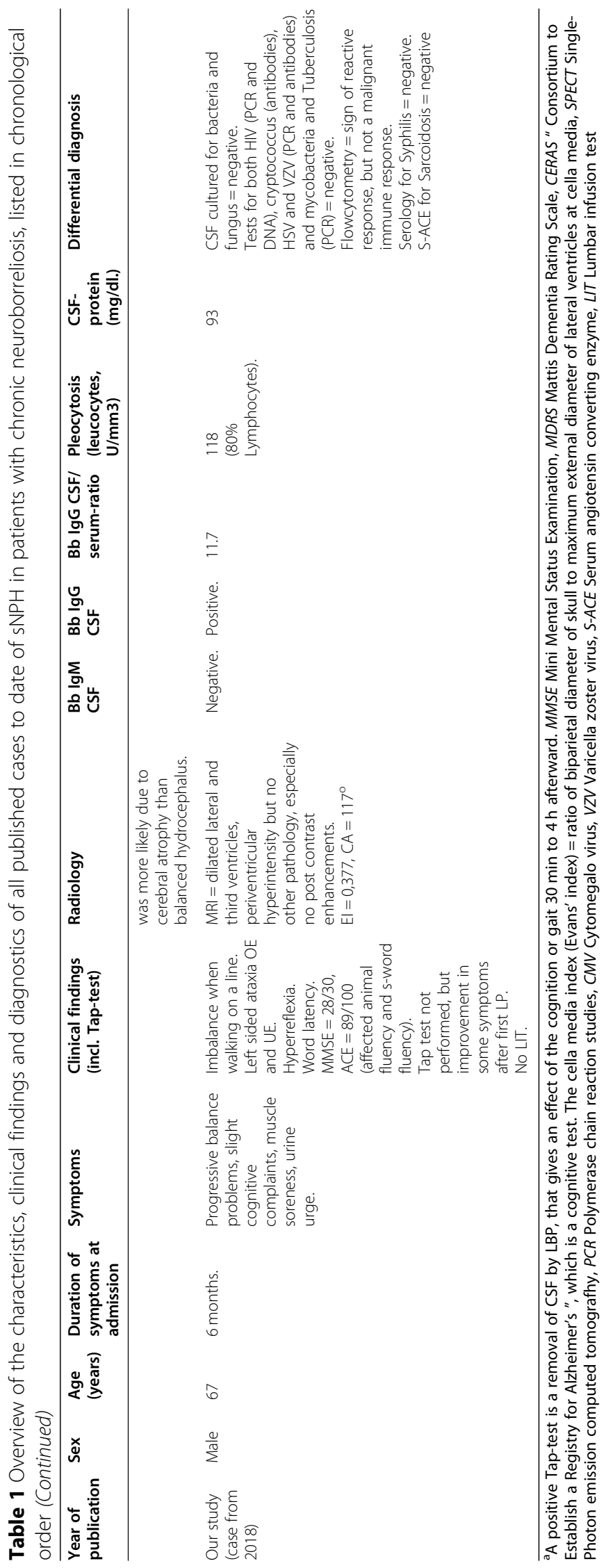


our case was treated with intravenous ceftriaxone $2 \mathrm{~g} . /$ day for between 2 and 5 weeks (the general agreement of treatment of Lyme disease [1]). All were eventually described with either full recovery or very limited noninvalidating remaining symptoms.

In only two cases did the radiological findings (12 and 18 months after $\mathrm{AB}$ ) follow the clinical improvement with decreased dilatation of the lateral ventricles. In 4 cases, the control scan was unchanged, while 3 cases didn't make a control scan.

In conclusion, this article is a rare presentation of chronic neuroborreliosis in the shape of sNPH, that have similar clinical presentation and treatment outcome as the prior 6 published cases. It shows the importance of early diagnosis and distinction from iNPH, as the cheap and minimally invasive procedure of LBP can shorten the symptom duration and completely prevent an unnecessary surgical intervention.

\section{Abbreviations}

AB: Antibiotic; ACE: Addenbrooke's Cognitive Examination; Bb: Borrelia Borgdorferi; CA: Callosal angle; CRP: C reactive protein; CSF: Cerebrospinal fluid; DESH: Disproportionately enlarged subarachnoidal space;

DNA: Deoxyribonucleic acid; DWMH: Deep white matter intensity; El: Evans Index; GP: General Practitioner; HIV: Human immunodeficiency virus: HSV: Herplex simplex virus; IgG, IgM: Immunoglobulin type $G$, immunoglobulin type M; iNPH: Idiopathic normal pressure hydrocephalus; LBP: Lumbar puncture; LIT: Lumbar infusion test; MMSE: Minimal Mental State Examination; MRI: Magnetic resonance imaging; NPH: Normal pressure hydrocephalus; PCR: Polymerase chain reaction; R-OUT: Outflow resistance; SACE: Serum angiotensin converting enzyme; sNPH: Secondary normal pressure hydrocephalus; VZV: Varicella zoster virus

\section{Acknowledgements}

We thank the patient for allowing us to share his details.

\section{Authors' contributions}

AMH has been one of the treating doctors in the course of the illness of the patient. LNG has been the primary author of the manuscript and in designing the table and figures with support and thorough medical and linguistic revision by AMH. All authors have read and approved the manuscript.

\section{Funding}

No funding was provided

\section{Availability of data and materials}

Raw data were generated at the patient registry of the public hospitals in Denmark. Derived data supporting the findings of this study are available from the corresponding author $L N G$ on request.

\section{Ethics approval and consent to participate}

Not applicable.

\section{Consent for publication}

The patient of whom the case report concerns have been informed about the publication and provided verbal and written consent for publication of the clinical case and the anonymized photo.

\section{Competing interests}

The authors declare that they have no competing interests.

\section{Author details}

'Department of Specialized Neurorehabilitation, Hvidovre Hospital, Kettegårds Allé 30, 2650 Hvidovre, Denmark. ${ }^{2}$ Department of Neurology,
Copenhagen University Hospital Bispebjerg, Bispebjerg Bakke, 2400

Copenhagen, Denmark.

Received: 22 August 2019 Accepted: 2 September 2020

Published online: 16 September 2020

References

1. Hansen K, Crone C, Kristoferitsch W. Lyme neuroborreliosis. Handb Clin Neurol. 2013:115:559-75.

2. Folstein M, Folstein SE, Mchugh PR, Department of Psychiatry, the New York hospital-Cornell medical center, Westchester division, White Plains, New York 10605, U. S. A. and \& Department of Psychiatry, University of Oregon Medical School, Portland, Oregon 97201, U. S. A. "MINI-MENTAL STATE", a practical method for grading the cognitive STATE of patients foe the clinician. J Psychiatry. 1975:12:189-98.

3. Mathuranath PS, et al. "A brief cognitive test battery to differentiate Alzheimer's disease and frontotemporal dementia". Neurology. 2000. https:// doi.org/10.1212/01.wnl.0000434309.85312.19

4. Hakim S, Adams RD. The special clinical problem of symptomatic hydrocephalus with Normal cerebrospinal fluid pressure. Observations on Cerebrospinal Fluid Hydrodynamics. 1965:307-27.

5. Daou B, Klinge $P$, Tjoumakaris $S$, Rosenwasser $\mathrm{RH}$, Jabbour P. Revisiting secondary normal pressure hydrocephalus: does it exist? A review. Neurosurg Focus. 2016:41:1-12.

6. Ishii $\mathrm{K}$, et al. Clinical impact of the callosal angle in the diagnosis of idiopathic normal pressure hydrocephalus. Eur Radiol. 2008;18:2678-83. https://doi.org/10.1007/s00330-008-1044-4.

7. Yamada S, Ishikawa M, Iwamuro Y, Yamamoto K. Choroidal fissure acts as an overflow device in cerebrospinal fluid drainage : morphological comparison between idiopathic and secondary normal-pressure hydrocephalus. Nat Publ Gr. 2016:1-11. https://doi.org/10.1038/srep39070.

8. Yamada S. Fluid distribution pattern in adult-onset congenital, Idiopathic, and Secondary Normal-Pressure Hydrocephalus : Implications for Clinical Care. Front Neurol. 2017;8:1-8.

9. Thomsen AM, Bgirgesen SE, Bruhn P, Gjerris F. Prognosis of Dementia in Normal-Pressure Hydrocephalus after a Shunt Operation. Ann Neurol. 1986; 20:304-10.

10. Abdool K, et al. Neurosyphilis With Normal Pressure Hydrocephalus and Dementia Paralytica: Serial Clinical, Laboratory and Radiological Correlations in the 21st Century". Neurol Int. 2016. https://doi.org/10.4081/ni.2016.6812.

11. Dhitinanmuang W, Chongtrakool P, Jitmuang A. Undiagnosed Cryptococcus gattii meningitis leading to subsequent ventriculoperitoneal shunt infection in a patient with symptoms of normal pressure hydrocephalus : case report and literature review; 2018. p. 1-7.

12. Danek A, Uttner I, Yousry T, Pfister HW. Lyme neuroborreliosis disguises as normal pressure hydrocephalus; 1996. p. 1743-5.

13. Druschky K, Grehl HSH. Sekundärer Normaldruckhydrozephalus; 1999. p. $556-9$

14. Etienne $M$, Carvalho $P$, Fauchais $A-L$, Pestel-Caron M, Doucet J, Chassagne $P$, Department of Geriatrics, CHU Rouen Rouen, F. Lyme Neuroborreliosis Revealed as a Normal Pressure Hydrocephalus. J Am Geriatr Soc. 2003;51: 579-80.

15. Aboul-enein F, Kristoferitsch W. Normal pressure hydrocephalus or neuroborreliosis? 2009. p. 58-61. https://doi.org/10.1007/s10354-008-0581-4.

16. Raffi T, Herbert L, Thomas K, Barbara P. Dramatic response to a 3-week course of ceftriaxone in late neuroborreliosis mimicking atypical dementia and normal pressure hydrocephalus. J Neurol Sci. 2018;366:146-8.

17. Desai A, Manek G, Krishnan AM, lorgoveanu C, Zaghloul A. Lyme Meningoencephalitis Masquerading as Normal Pressure Hydrocephalus. Cureus. 2018;10:1-4

18. Andersson C, Nyberg C, Nyman D. Rapid development of dementia of an elderly person, diagnosis and successful treatment. Duodecim. 2004;120(15): 1893-6.

19. Rainer M. Demenz durch Neuroborreliose. Psychopraxis. 2011. https://doi. org/10.1007/s00739-011-0304-2.

20. Franceschi AM, et al. Diagnosis of Normal-Pressure Hydrocephalus : Use of Traditional Measures in the Era of Volumetric MR. Radiology. 2017;285:197-205.

21. Kristoferitsch $W$, et al. Secondary dementia due to Lyme neuroborreliosis; 2018. p. 468-78. https://doi.org/10.1007/s00508-018-1361-9.

22. Blanc F, Philippi N, Cretin B, Kleitz C, Berly L. Lyme Neuroborreliosis and Dementia. J Alzheimers Dis. 2014;41:1087-93. 
23. Bransfield RC. Neuropsychiatric Lyme Borreliosis : An Overview with a Focus on a Specialty Psychiatrist 's Clinical Practice; 2018. https://doi.org/10.3390/ healthcare6030104.

24. Schwenkenbecher $\mathrm{P}$, et al. Common and uncommon neurological manifestations of neuroborreliosis leading to hospitalization. BMC Infect Dis. 2017:1-10. https://doi.org/10.1186/s12879-016-2112-z.

25. Marmarou A, Ph D, Bergsneider M. Development of Guidelines for Idiopathic Normal Pressure Hydrocephalus. Neurosurgery. 2005;57:2-4.

26. Masatsune I, Yasushi I, Shigeki Y. EBM Of neurosurgical disease in Japan clinical guidelines for idiopathic Normal pressure hydrocephalus. Nat Publ Gr. 2004:44:222-3.

27. Williams $\mathrm{M}$, Relkin N. Diagnosis and management of idiopathic normalpressure hydrocephalus. Neurol Clin Pract. 2013:375-85.

28. Lebech A-MK, Hansen K. Lyme borreliosis--the most frequent vector-borne infection in Denmark. Ugeskr Laeger. 2004;166:2431-3.

29. Dessau RB, et al. To test or not to test? Laboratory support for the diagnosis of Lyme borreliosis: a position paper of ESGBOR, the ESCMID study group for Lyme borreliosis. Clin Microbiol Infect. 2018;24:118-24.

\section{Publisher's Note}

Springer Nature remains neutral with regard to jurisdictional claims in published maps and institutional affiliations.

Ready to submit your research? Choose BMC and benefit from:

- fast, convenient online submission

- thorough peer review by experienced researchers in your field

- rapid publication on acceptance

- support for research data, including large and complex data types

- gold Open Access which fosters wider collaboration and increased citations

- maximum visibility for your research: over $100 \mathrm{M}$ website views per year

At BMC, research is always in progress.

Learn more biomedcentral.com/submissions 